\title{
Differential expression patterns of conserved miRNAs and isomiRs during Atlantic halibut development
}

\author{
Teshome T Bizuayehu', Carlos FC Lanes', Tomasz Furmanek², Bård O Karlsen', Jorge MO Fernandes',
} Steinar D Johansen ${ }^{1,3}$ and Igor Babiak ${ }^{1 *}$

\begin{abstract}
Background: MicroRNAs (miRNAs) play a major role in animal ontogenesis. Size variants of miRNAs, isomiRs, are observed along with the main miRNA types, but their origin and possible biological role are uncovered yet. Developmental profiles of miRNAs have been reported in few fish species only and, to our knowledge, differential expressions of isomiRs have not yet been shown during fish development. Atlantic halibut, Hippoglossus hippoglossus L., undergoes dramatic metamorphosis during early development from symmetrical pelagic larval stage to unsymmetrical flatfish. No data exist on role of miRNAs in halibut metamorphosis.

Results: miRNA profiling using SOLiD deep sequencing technology revealed a total of 199 conserved, one novel antisense, and one miRNA* mature form. Digital expression profiles of selected miRNAs were validated using reverse transcription quantitative $P C R$. We found developmental transition-specific miRNA expression. Expression of some miRNA* exceeded the guide strand miRNA. We revealed that nucleotide truncations and/or additions at the $3^{\prime}$ end of mature miRNAs resulted in size variants showing differential expression patterns during the development in a number of miRNA families. We confirmed the presence of isomiRs by cloning and Sanger sequencing. Also, we found inverse relationship between expression levels of sense/antisense miRNAs during halibut development.
\end{abstract}

Conclusion: Developmental transitions during early development of Atlantic halibut are associated with expression of certain miRNA types. IsomiRs are abundant and often show differential expression during the development.

\section{Background}

Atlantic halibut, Hippoglossus hippoglossus L., the largest flatfish of Atlantic Ocean, is a species of commercial interest to the aquaculture industry. Halibut's early developmental stages are prolonged and morphologically defined [1,2]. The critical developmental stages, when dramatic changes in signaling, physiology and morphology occur, include: (i) maternal to zygote transition $(\mathrm{MZT})$, when maternally stocked transcripts are degraded and zygote transcripts take control over the development; (ii) organogenesis, when the germ layers are formed; (iii) hatching, when the embryo becomes a free-swimming larva; (iv) first feeding, when active movement, visualization, recognition of prey, and

\footnotetext{
* Correspondence: igor.babiak@uin.no

'University of Nordland, Faculty of Biosciences and Aquaculture, Postbox 1490, 8049 Bodø, Norway

Full list of author information is available at the end of the article
}

exogenous feeding begin; and (v) metamorphosis, the most dramatic morphological and behavioral change in a flatfish during the transition from a symmetric postlarval to an asymmetric juvenile stage, when migration of one eye towards the other one occurs across the skull $[1]$.

MiRNAs are small (18 - 26 nucleotides) non-coding RNAs that control and regulate target genes, mostly in a suppressive way $[3,4]$. In vertebrates, miRNAs are important in various developmental processes including MZT, maintenance of cell and tissue identity, organ development, hematopoietic lineage modulation, adipocyte differentiation, and imprinting [5]. Developmental profiles of miRNAs have been reported in few fish species only, including model species such as zebrafish (Danio rerio), fugu (Takifugu rubripes), tetraodon (Tetraodon nigroviridis), and medaka (Oryzias latipes). Recently, miRNAs have been characterized in Atlantic

\section{(Ciomed Central}


cod (Gadus morhua), Asian seabass (Lates calcarifer) and Japanese flounder (Paralichthys olivaceus) [6-10]. Functional studies have been performed only on zebrafish and medaka [11-14]. These studies showed the conservation of miRNA sequences among distantly related teleosts and variations in the expression pattern of selected miRNAs during the development [14], and indicated that miRNA sequence conservation did not reflect spatial or temporal conservation of expression [15]. Some species-specific miRNAs have been found $[6,16]$.

IsomiRs are size variants of miRNAs. Their occurrence has been observed along with the main miRNA types $[17,18]$, but their origin and possible biological role are not known yet. Modifications and size variations have been reported during miRNA maturation in different organisms [19-24]. These alterations have been suggested to influence stability, effectiveness, protection or degradation of mature miRNAs [19-23,25]. Imperfect cleavage of pri- and/or pre-miRNAs by Drosha and Dicer, respectively, affects mature miRNAs size and indicates that size heterogeneity could be an enrichment strategy of miRNAs for target diversification [24]. IsomiRs can play important roles under both physiological and disease conditions $[17,26,27]$. To our knowledge, differential expressions of isomiRs have not yet been shown during ray-finned fish development.

Various approaches have been used to characterize and profile miRNAs with or/and without prior knowledge of sequences. The SOLiD high throughput sequencing platform has been used to identify and characterize small RNAs in various species $[8,28,29]$. The depth of coverage from SOLiD platform is a considerable advantage over other comparable platforms, such as the 454 pyrosequencing platform [8]. We applied high-throughput SOLiD sequencing to identify and profile Atlantic halibut miRNAs during the development. We discovered putative novel miRNAs and isomiRs, and demonstrated that isomiRs were differentially expressed during halibut development.

\section{Results}

\section{Sequence statistics and miRNA identification}

The last 15 color reads from the 3' end, which were poor in quality, were removed from all tags (Figure 1A). This pre-processing did not affect the actual size of miRNAs. About 72 million reads were obtained from eight developmental stages of Atlantic halibut. Out of it, 70.7\% were longer than 15 nucleotides, nt (Additional File 1). Length distribution of all reads showed three peaks (Figure 1B), with the majority (54.5\%) being between 16 and $26 \mathrm{nt}$ long. Reads longer than $15 \mathrm{nt}$ were composed of $2.2 \%$ mitochondrial transcripts, $8.2 \%$ tRNA, and $0.8 \%$ rRNA sequences. The size distribution of reads that mapped to different databases is shown in
Additional File 2. On average, $7.2 \%$ of these reads were mapped to known miRNAs in all examined developmental stages with the highest percentage $(14.9 \%)$ in the first feeding stage and the lowest $(0.2 \%)$ in the blastula stage. In addition, 4.5 and $0.16 \%$ of the reads were mapped to halibut ESTs and to other non-coding RNAs, respectively (Figure 1C). Remaining reads were unmapped.

Most of conserved fish miRNA families annotated in miRBase release version 16 were identified in the present study, with except for miR-208 and miR-155 families. The identified families consisted of 199 types of conserved miRNAs (Additional File 3). miRNA diversity was increasing along with the developmental advancement (Additional File 4).

We found extensive length variation in several miRNAs (Figure 1D and Additional File 5). These modifications were more pronounced at the 3' end, where $46 \%$ of miRNAs had added bases and $24 \%$ had missed bases compared to the reference sequences. Likewise, the majority (67\%) of mismatches was observed on the last six nucleotides from 3' end of mature miRNAs, but $8 \%$ of the miRNAs showed a mismatch at the first base of the 5' end.

\section{Expression profile of conserved miRNAs}

Expression patterns of some miRNA families were associated with certain developmental stages (Figure 2). Hierarchical clustering showed four major expression patterns: a) early embryonic expression, which might be related to MZT and post-MZT clearance of maternal transcripts; b) embryonic expression, during organogenesis and hatching; c) feeding larvae expression, when larvae undertook exogenous feeding; and d) metamorphosis expression, during larva-to-juvenile transition.

miRNA diversity and expression intensity varied among the developmental stages. At early stages (blastulation and gastrulation), fewer types of miRNAs were found than in later stages (Additional File 4). The most dominant miRNAs at earlier stages belonged to the miR-430 family, showing the highest expression during the gastrulation and ceasing after hatching (Figures 3A and 4).

Among miRNAs involved in the pattern formation and maintenance of cellular and tissue identity, miR-10, miR-17, miR-184, or miR-196 families were relatively highly expressed throughout somitogenesis and hatching (Figures 2, 3B and 3C), and miR-130 family was highly expressed around hatching stage (Figure 3D). Other miRNAs, such as miR-9, miR-103 family, miR-107 and miR-124 were expressed intensively during the first feeding stage (Figures 3E and 4).

Peak of expression of a number of miRNAs, such as miR-122, miR-192, miR-199, miR-206 and miR-210 was associated with specific developmental transition points (Figures 2, 3F and 4; Additional Files 3 and 4). 

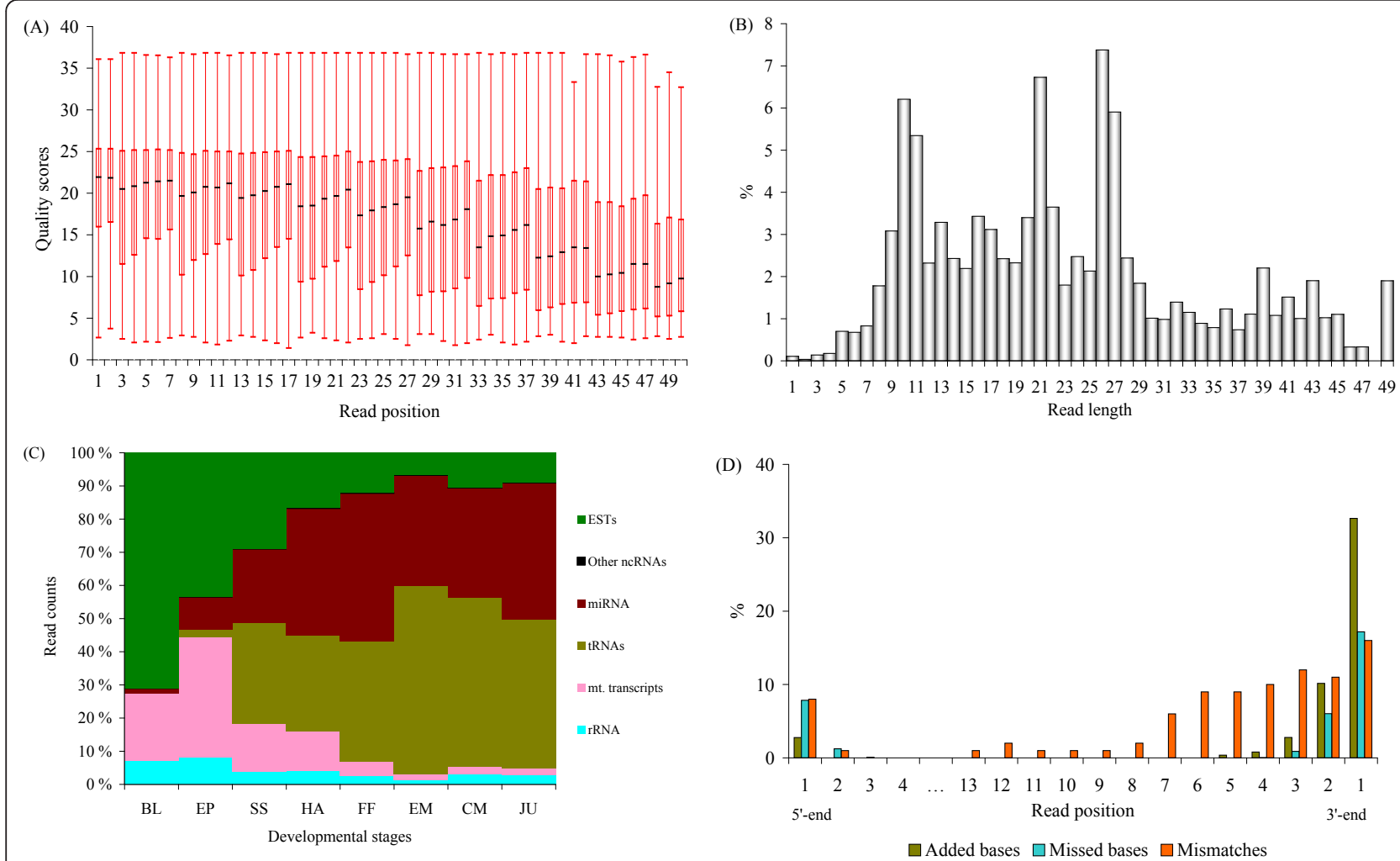

Figure 1 Read statistics for deep sequencing of Atlantic halibut small non-coding RNA. A) Quality score of reads averaged at each position for all samples; the box indicates inter-quartile range, where the lower boundary shows $1^{\text {st }}$ quartile and the top boundary shows the $3^{\text {rd }}$ quartile with the median line in between. B) Read length distribution after removal of adaptor sequences. The three peaks of read size frequencies represent very small RNA, miRNA/siRNA, and piRNA (see details in Results). C) Proportion of reads mapped to different databases excluding unmapped reads; other non-coding RNAs are < 1\% in all stages. BL, EP, SS, HA, FF, EM, CM, and JU stand for blastula, epiboly, somitogenesis, hatching, first feeding, early metamorphosis, climax metamorphosis and juvenile developmental stages, respectively. D) Overall average mismatches, missed and added bases in halibut mature miRNAs compared to mature miRBase reference sequences.

In some cases the passenger strand miRNAs were highly expressed compared to the guide strand. For example, miR-133a* and miR-140* had at least threefold higher expression compared to their counterparts miR-133 and miR-140, respectively (Figure 5). At somitogenesis, the expression of miR-133b* was comparable to that of the guide strand, whereas miR-30 $\mathrm{e}^{*}$ expression at this stage was two times higher than the expression of the guide strand. However, in the later stages, the expression of miR-30e" and miR-133b* was dissipated comparing to their counterparts miR-30e and miR-133b, respectively. In addition, the expression of miR-203b* was higher than miR-203b in all examined stages of the development (Figure 5).

Our digital expression profile results were positively validated by RT-qPCR assay $(r=0.90,0.99,0.62,0.72$, $0.65,0.99,0.77$ and 0.85 for let-7a, miR-9, mir-19b, miR-24, mir-122, miR-124, miR-145, and miR-430c, respectively; Figure 4).

\section{Differential expression of isomiRs during halibut development}

Some miRNAs with up to three missed or added nts from the 3' end were expressed differently compared to full-sized miRNAs (Figure 6A-I). We found that the expression of isomiRs varied and some isomiRs showed distinct quantitative patterns throughout the development. This pattern was clearly visible in miR-301c, where single nt-added isomiR showed constant increase in the expression from blastula stage towards the juvenile stage, in contrast to the three nts-added isomiR in which expression declined during the development (Figure 6A). Also, single nt-missed and single nt-added isomiRs of miR-17a showed the same expression level at blastula stage, but in the later developmental stages they followed opposite trends (Figure 6B). Truncated miR$19 \mathrm{~b}$ isomiRs showed a reciprocal expression pattern throughout the development compared to the non-truncated counterpart (Figure 6C). Stage-specific expression 


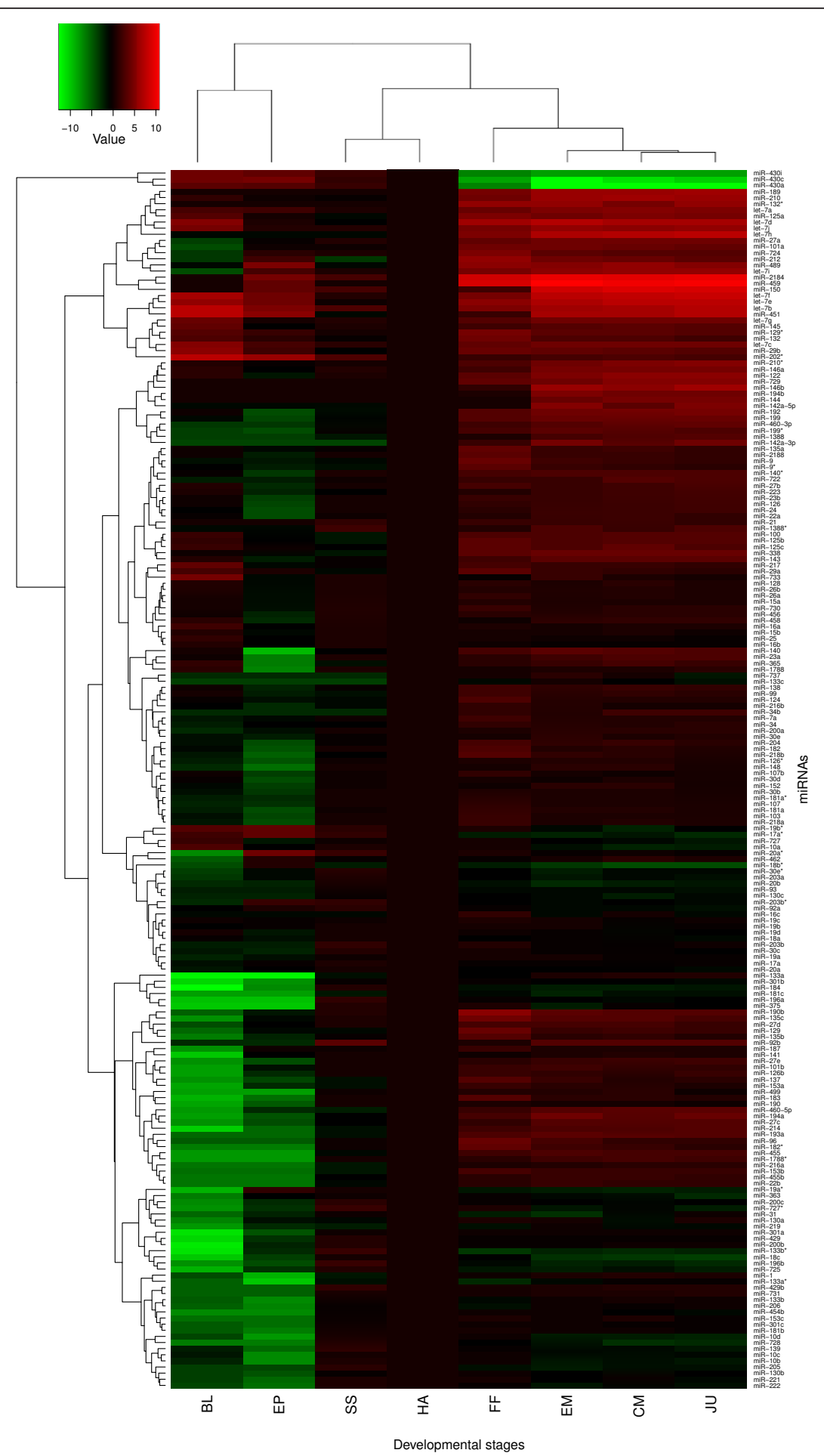

Figure 2 The heatmap of identified miRNAs during Atlantic halibut early ontogenesis (see Figure 1C legend for abbreviations). The heatmap is obtained using R program version 2.12 .0 (Euclidean distance, average linkage algorithm). There are 199 rows and 8 columns

corresponding to each miRNA and developmental stage, respectively. The heatmap was drawn on log 2 normalized read counts in relation to the expression at hatching stage as a reference (no color), and downregulation and upregulation were denoted with shades of green and red, respectively. 


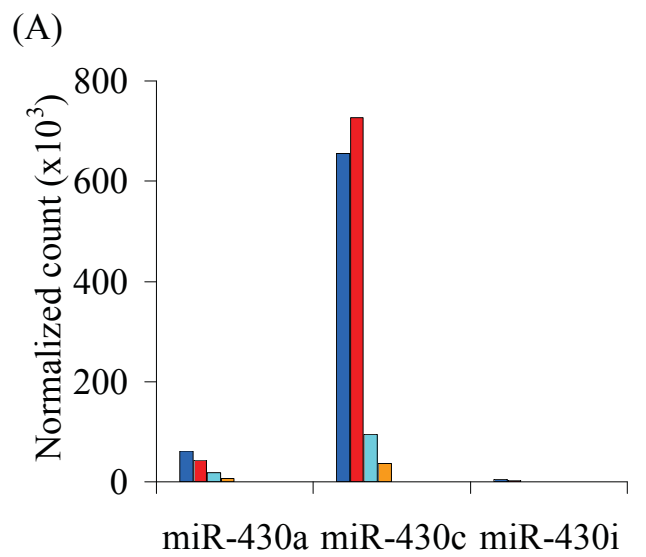

(C)

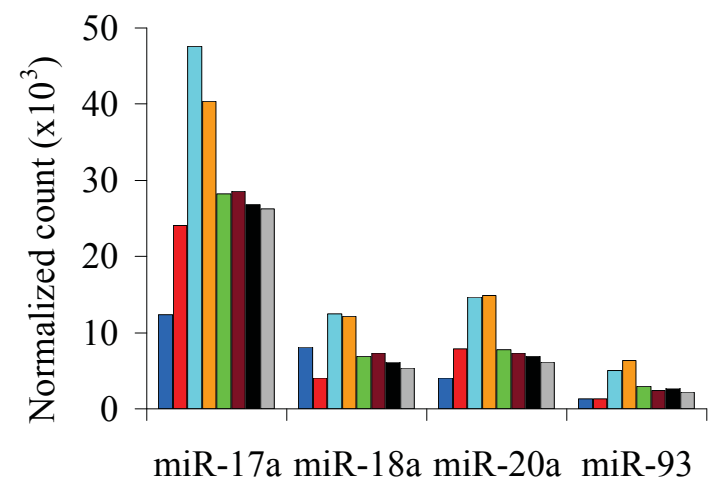

(E)

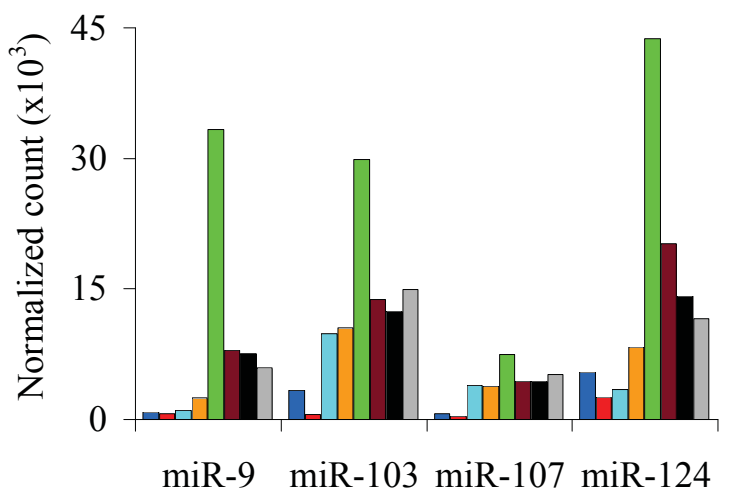

(B)

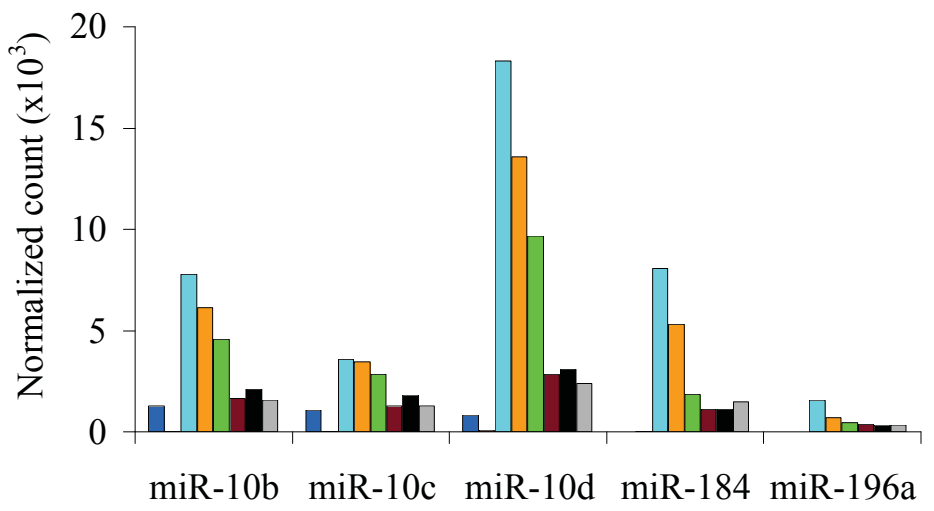

(D)

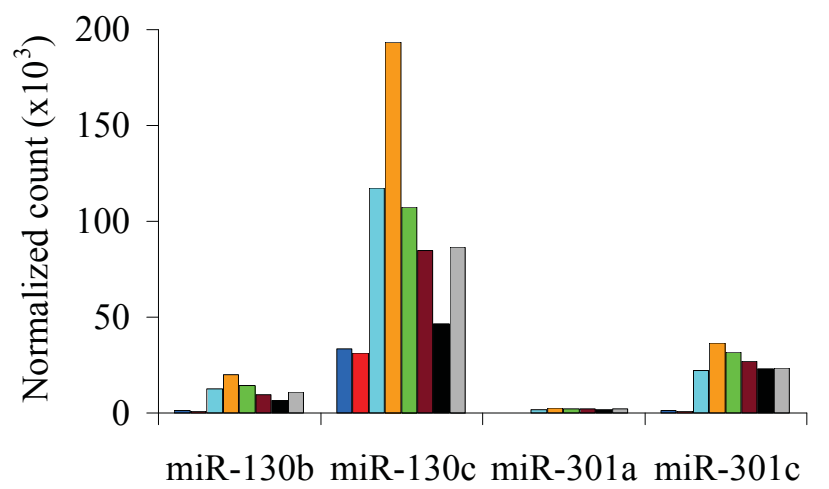

(F)

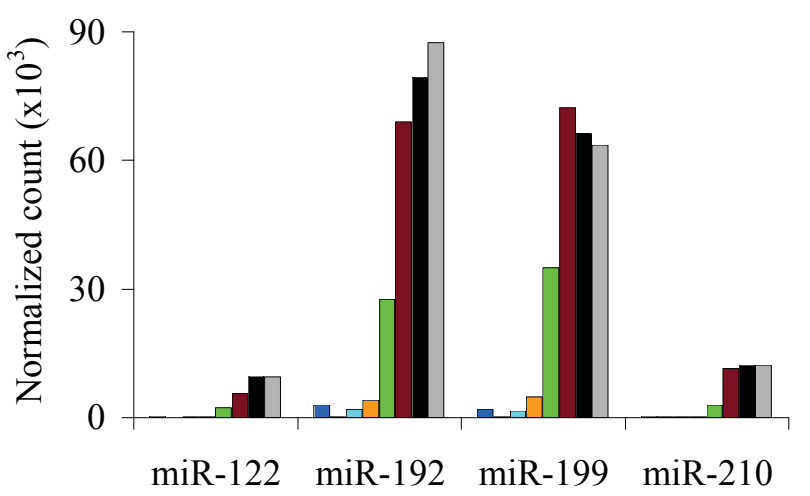

$\square$ BL $\square$ EP $\square$ SS $\square$ HA $\square$ FF $\square$ EM $\square \mathrm{CM} \square$ JU

Figure 3 Normalized read counts of selected miRNAs during eight stages of Atlantic halibut development. See Figure $1 \mathrm{C}$ legend for specification of developmental stages.

pattern of truncated isomiRs was observed in miR-203a (Figure 6E) and differential expression was observed in other tested isomiRs (Figure 6F-I). Although most of the added nucleotides were template nucleotides, there were non-template nucleotides in some of the isomiRs, such as miR-1-1, miR-125a, miR-203a, miR-206, and miR-375
(Additional File 5). The prominent non-template nucleotides were uracil or adenine, reaching $11.8 \%$ and $5.3 \%$ of number of reads in $\mathrm{miR}-1$ and $\mathrm{miR}-375$, respectively. Guanine additions were below $1 \%$ of reads, and cytosine additions were less than $0.01 \%$ (Additional File $5)$. Single nt-additions at $5^{\prime}$ end were frequent in miR- 


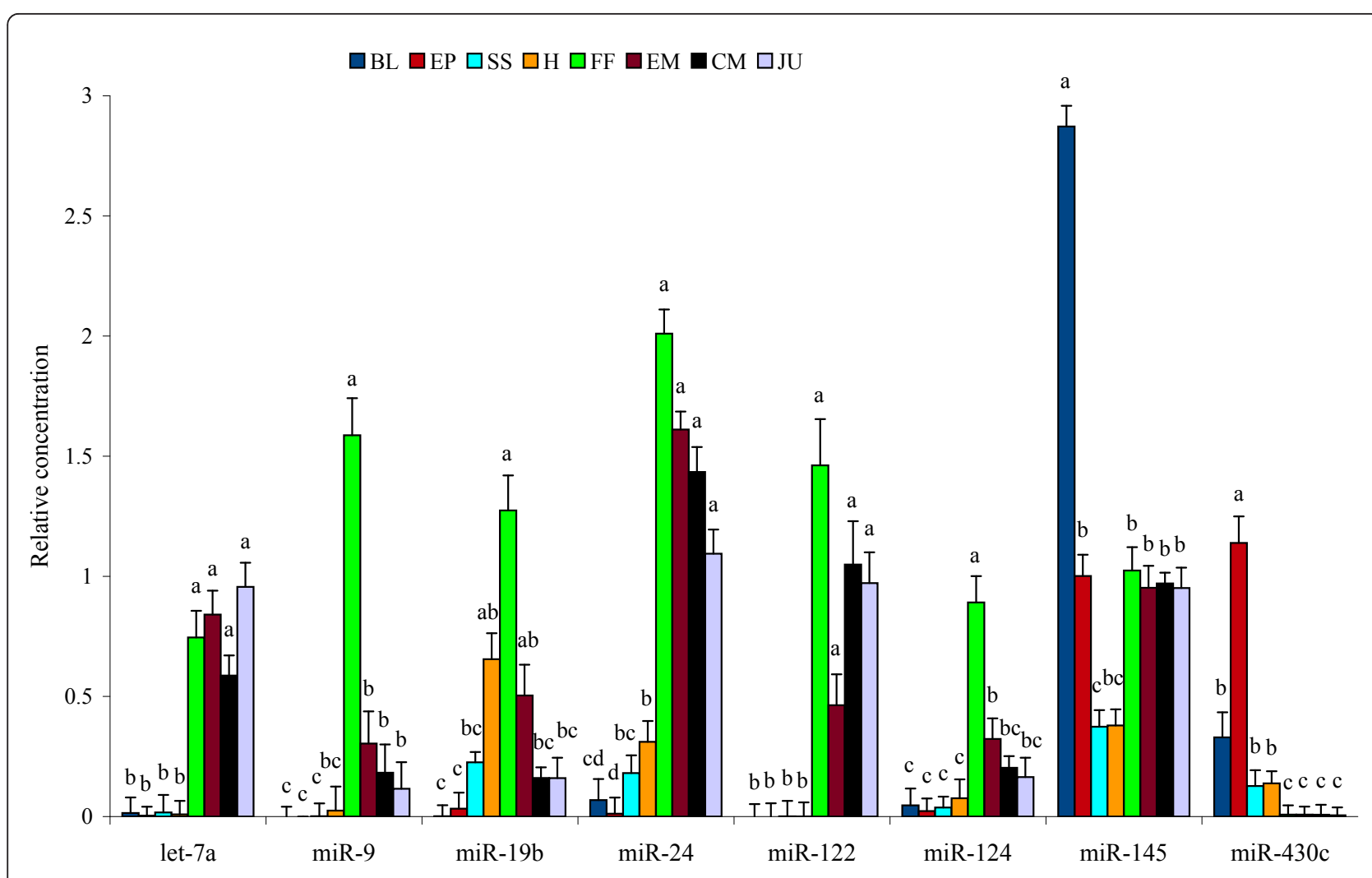

Figure 4 Relative expression of selected miRNAs using RT-qPCR. Different letters indicate statistically significant differences $(P<0.05)$ between means. Error bar is S.E.

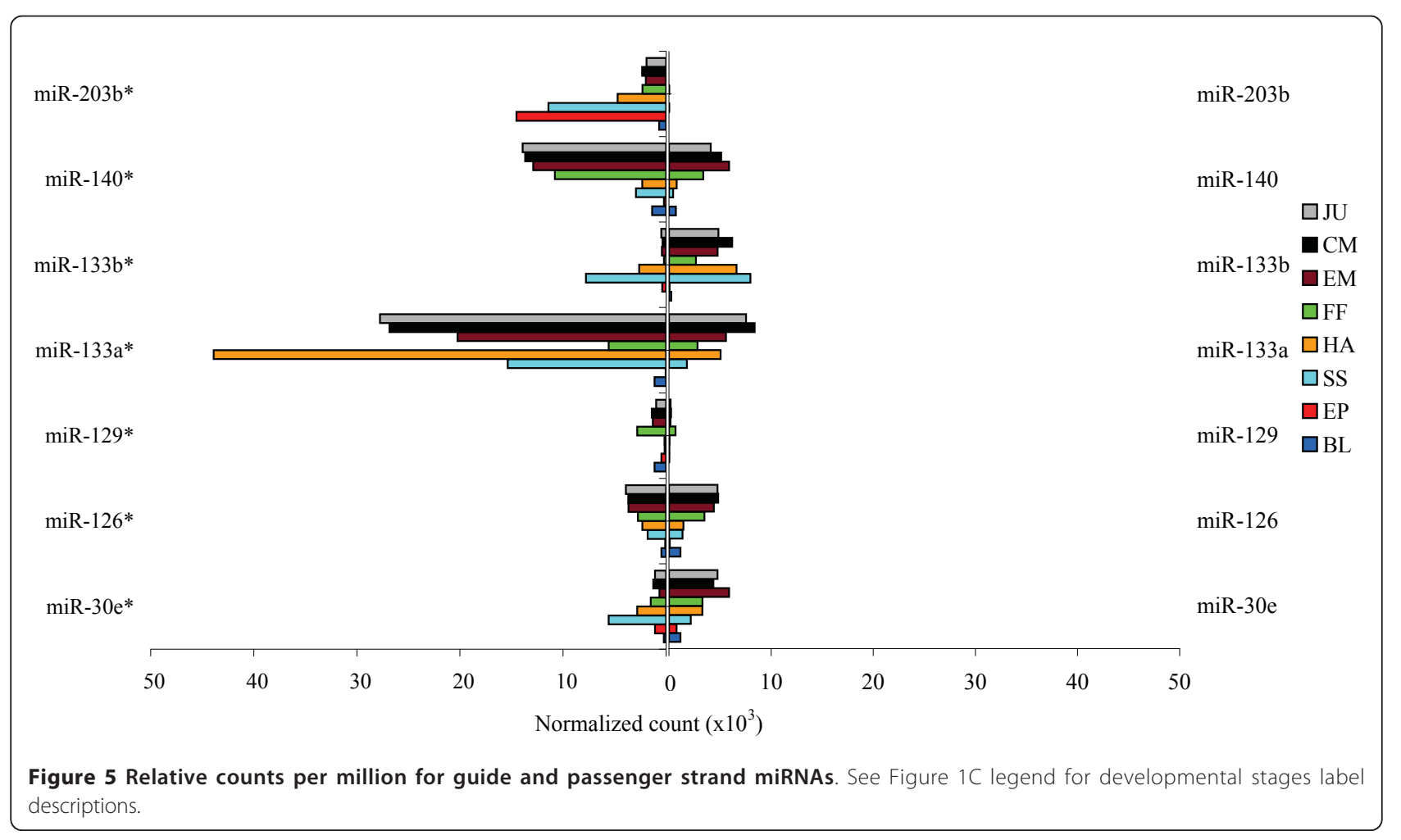




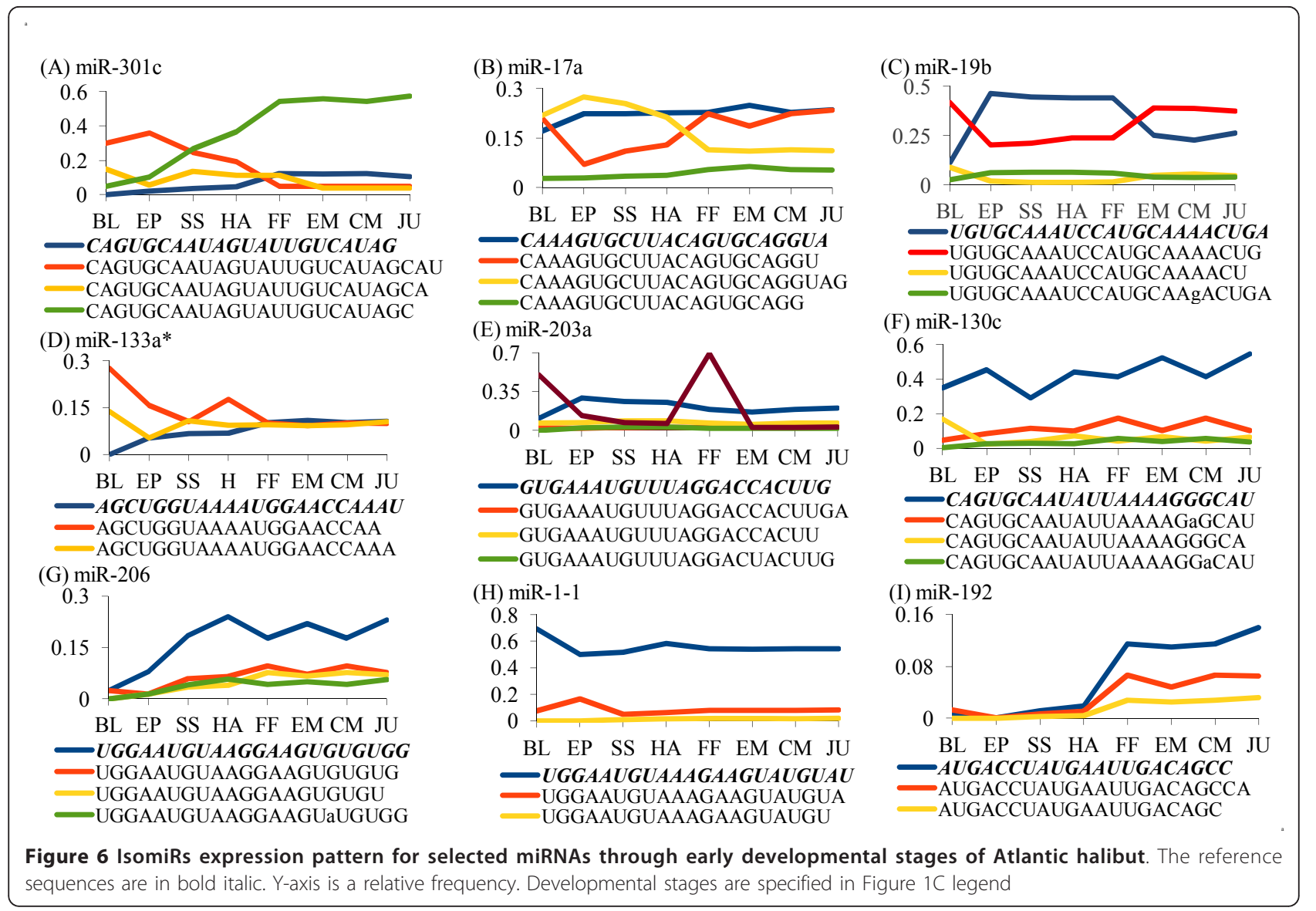

204 (10.7\%), miR-214 (22.4\%), miR-22a (6.9\%), and miR455 (19.5\%). Single nt additions at 3' end exceeded $60 \%$ frequency, in a number of miRNAs, such as miR-10b, miR-30c miR-126a, miR-135b, and miR-430d (Additional File 5).

We performed cloning and Sanger sequencing to verify the presence of isomiRs. Fifty out of 234 sequenced clones had miRNAs inserts. These sequences aligned to 30 different types of miRNAs. Clones containing miR-17 sequence showed size variations, including three nts truncation and addition at both 5' and 3' ends. Untemplated adenine at the 3 ' end of miR-17 was found. miR206 clone sequences were truncated by 2 nts from the 3 ' end (Additional File 6).

\section{Identified novel miRNAs}

We identified one precursor miRNA from EST dataset (Genebank ID: EB030760.1) having sequence similarity with mammalian and bird miR-147. We also found reads of a putative novel miR-147* sequence in the deep sequencing dataset (Figure 7A).

Antisense miRNA of reverse complementarity to miR204 with one mismatch and additional nucleotides at the 3' end was another putative novel miRNA (Figure
7B). The expression pattern of the antisense (miR204AS) throughout the development was different from that of the miR-204. The ratio antisense:sense expression was the highest at the blastula stage, then declined as the development progressed. Sense miRNA expression was higher than antisense from the first feeding stage onwards (Table 1).

\section{Discussion}

\section{Characterization Atlantic halibut small RNAs}

The three distinct peaks in the size distribution of Atlantic halibut small RNA consisted of $26-27$ nts cluster corresponding to piwi-interacting RNAs, 20 - 22 nts cluster containing miRNAs and short interfering RNAs, and 10-11 nts cluster of unknown origin and function (Figure 1B). To our knowledge, these very short RNAs have not been characterized yet; previously, they were considered as degradation products and removed from the datasets during the data processing $[30,31]$.

The number of reads in size range between 16 and 26 nts was high (54.5\%) indicating that the libraries were enriched with miRNAs. miRNAs are classified into different families based on their seed sequence similarity 


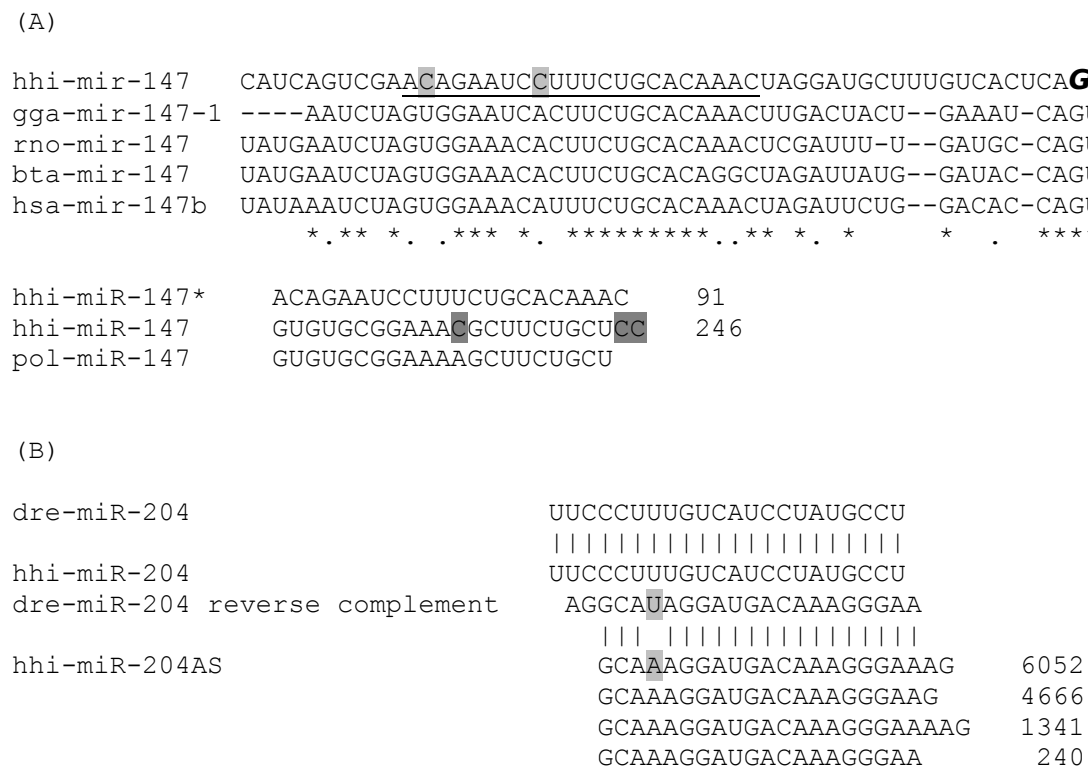

(B)

dre-miR-20 4

hhi-miR-204

dre-miR-204 reverse complement

hhi-miR-204AS

Figure 7 A) Atlantic halibut mir-147 precursor sequence in comparison with human, rat, chicken, and cattle precursor sequences. B) Alignment and sequence of novel antisense miRNA in Atlantic halibut. Mature guiding strand miRNA sequences are indicated in italic and bold, while miRNA* sequences are underlined. Differences in nucleotide among species are highlighted gray. Star (*) indicates the conservation among all species, whereas dot (.) indicates partial conservation. Numbers on the right indicate overall SOLiD read counts for the respective sequence.

that span $2-8$ nucleotide positions from 5' end of mature miRNA [6]. This conservation allows comparison among species. In the present study, all but two known fish miRNA families were identified, confirming high conservation of miRNAs among teleosts.

\section{Expression profile of conserved miRNAs and halibut development}

Atlantic halibut has morphologically defined developmental stages that can be inferred along with the expression of various genes [32-35]. The increase in miRNA diversity along with the developmental advancement (Additional File 4) indicates the importance of miRNAs in the tissue and organ differentiation, similar to mice [36], chicken [37], other fish [38,39], and

Table 1 The ratio between antisense and sense strands expression of miR-204 during Atlantic halibut development.

\begin{tabular}{ll}
\hline Developmental stages & Anti-sense:sense ratio \\
\hline Blastula & 872.5 \\
Epiboly & 195.42 \\
Somites & 4.78 \\
Hatching & 1.41 \\
First feeding & 0.07 \\
Early metamorphosis & 0.2 \\
Climax metamorphosis & 0.35 \\
Juvenile & 0.49
\end{tabular}

invertebrates [40]. It has been demonstrated that miRNAs play pivotal roles in the developmental progression and maintenance of tissue identity in several species $[11,39,41-44]$. In the present study, miRNAs were expressed either uniquely or ubiquitously during the development (Figure 2).

Maternal-zygotic transition (MZT) was the earliest developmental transition investigated in the present study. In mammals, the onset of MZT occurs during the three first cell divisions [45], while in most teleosts it takes place around the beginning of gastrulation [46]. Maternal transcripts clearance and MZT in zebrafish and medaka is associated with the expression of miR430 family $[11,12,39,47]$. Similarly, we demonstrated previously that maternal transcripts decline around MZT in Atlantic halibut [48]. High expression of miR430 at the onset of gastrulation (Figures 2 and 4) suggests that MZT in Atlantic halibut is facilitated by miRNAs.

We found that miR-10, miR-17, miR-184, or miR-196 families were relatively highly expressed throughout somitogenesis and hatching (Figures 2, 3B, C). miR-17 family is involved in early development and functional cell differentiation in mammals $[49,50]$. High expressions of miR-17 family during halibut organogenesis can imply this assertion. miR-10 and miR-196 have been identified along with Hox genes cluster in fruit fly, zebrafish, pufferfish, mouse, and human [51,52]. miR-130 
family, highly expressed around halibut hatching stage (Figure 3D), have been implicated in regulation of angiogenesis [53]. Thus, the miR-130 family could also promote development of the blood and lymphatic vascular systems in halibut.

Some miRNAs, such as miR-9, miR-103 family, miR107, and miR-124 were expressed intensively during the first feeding stage (Figures $3 e$ and 4). Previous studies have shown exclusive expression of some miRNAs in certain tissue types $[47,54]$. For example, in zebrafish, miR-9 is expressed in differentiated neurons, and miR124 is broadly expressed in both proliferative and differentiated brain cells $[47,54]$. The expression of miR-9 and miR-124 in halibut was synchronized with the beginning of exogenous feeding, which requires intensified neural functions for active movement, identification, and capturing of a prey. Also, miR-103 was expressed in similar fashion during the first feeding. miR-103 is involved in intestinal cell proliferation in mouse, [55], and in zebrafish it is expressed in the gut [39]. High expression of miR-103 during the start of exogenous feeding in halibut might be related to intestinal growth.

Various miRNAs, including miR-192 and miR-199, are differentially expressed during metamorphosis of Japanese flounder [9]. In the present study, miR-122, miR192, miR-199 and miR-210 were among miRNAs highly expressed during halibut metamorphosis (Figures 2 and 4). Erythropoiesis is regulated by many miRNAs including miR-210 [56-58]. Specific expression of a number of miRNAs during halibut metamorphosis indicates the possible involvement of miRNAs in this developmental transition.

Relatively high expression of miRNA"'s have been reported during zebrafish development [39] and in Japanese flounder [9]. Our results support these findings. In a number of cases halibut miRNA* expression exceeded miRNA expression and showed development-specific pattern (Figure 5). miRNA*s can be part of the posttranscriptional regulatory network during the development [59].

\section{IsomiR expression during halibut development}

Size variants found in multiple miRNAs during Atlantic halibut development (Figure 6 and Additional File 5) raise the question whether they play any regulatory role. The presence of truncated or added template nucleotides in 89 out of 199 miRNAs in this study is similar to that reported in few other species $[18,60]$.

Frequent 5' nucleotide addition observed in some of the miRNAs (Additional File 5) might be explained as imperfect cleavage of pri- and/or pre-miRNAs by Drosha and Dicer micro processors. Starega-Roslan et al. [24] have shown that the structure of hairpins including the symmetry of internal loops and number of nucleotides on bulges affects size heterogeneity of mature miRNAs in human cell lines. Other possible explanation is that miRNA size variants can result from paralogue genes [26], or different allelic forms.

A number of reads in the present study showed significant additions of $\mathrm{A}$ or $\mathrm{U}$. The presence of non-template nucleotides at the 3' end in our datasets (Additional file 5) may indicate post-maturation modifications of miRNAs, as shown in mammals and insects $[16,18,26,61,62]$. miRNA modifications including 3'-methylation and adenosine-to-inosine editing have been reported in several organisms [19-23]. These changes are implicated in the stability, protection and destruction of miRNAs, as well as in determining miRNAs efficiency in loading to Argonaute protein complex $[16,25,63,64]$.

We found isomiRs in both cloning and next generation sequencing datasets; for example, miR-17a, miR206, and miR-204 had identical isomiRs (Additional Files 5 and 6). Similar results have been reported in different organisms and platforms $[26,27,60]$. All those data suggest that end modifications in mature miRNA could unlikely be a processing error.

Differential expression of isomiRs has recently been reported during Drosophila development [18]. Also, it has been shown that both 5' and 3' truncated versions of miRNAs were incorporated in RNA-induced silencing complex (RISC) [27], indicating possible functional role of isomiRs. We demonstrated that isomiRs showed clearly distinctive expression patterns during the development of halibut (Figure 6). Our data suggest possible diversification strategy for selective exclusion/inclusion of certain target genes from/for repressive control during the specific stages of development. Therefore, we hypothesize that isomiRs can be legitimate and biologically meaningful forms of mature miRNAs, which deserve further investigation.

\section{Novel miRNAs in Atlantic halibut}

Discovery of species-specific miRNAs largely depend upon the availability of genomic resources, since mapping and extracting precursor miRNA sequences is a crucial step of the process. Given the limitation of adequate genome resources for Atlantic halibut, we identified only single precursor miRNA from Atlantic halibut EST data using stringent criteria. Although this precursor miRNA was characterized in mammals and chicken $[6,26,36,65,66]$, the miRNA* sequences have not been characterized yet [6]. The other novel miRNA was antisense miRNA (Figure 7B). Transcription of miRNA iab4 locus from both DNA strands shows developmental importance of sense/antisense miRNAs in flies as well as in mammals [67]. Deep sequencing data revealed miRNA sense/antisense expression during silkworm development [30]. The gradual shift between the 
antisense and sense miRNA expression during the Atlantic halibut development suggests that antisense miRNAs can have a functional role.

\section{Conclusions}

We have identified 199 conserved miRNAs, one miRNA*, and one novel antisense miRNA during Atlantic halibut ontogenesis. We profiled their expression pattern using SOLiD deep sequencing technology and verified it using RT-qPCR. We demonstrated differential expression of miRNAs throughout major developmental transitions. Some miRNA*'s showed higher expression than their miRNA counterparts. Also, we found reciprocal expression levels of sense/antisense miRNAs during halibut development. We demonstrated differential expression patterns in a number of isomiRs. Whether isomiRs are biologically meaningful it will be addressed in the future investigations.

\section{Methods}

\section{Experimental animals}

Fish were treated and samples were obtained following the procedures for animal experimentation provided by National Animal Research Authority in Norway. Gametes were obtained from broodstock fish held at the Marine Research Station of the University of Nordland, Bodø, Norway. In total, eggs from 7 females were fertilized and incubated in filtered 33\% sea water following the procedures described by Babiak et al. [68]. Briefly, eggs from each individual female were incubated separately in flow-through conical $280 \mathrm{l}$ tanks at $5.0 \pm 0.5{ }^{\circ} \mathrm{C}$ until hatching. Larvae were then transferred to conical $500 \mathrm{l}$ tanks for first feeding and water temperature was gradually increased to $12 \pm 1^{\circ} \mathrm{C}$. Larvae were fed Artemia salina strain Franciscana (Salt Creek Inc, Utah, USA), while weaned larvae and juveniles were fed formulated dry-feed (Gemma, Skretting, Norway) ad libitum.

\section{Sampling and RNA extraction}

Atlantic halibut embryos from each female progeny group were collected at the following developmental stages: blastula (2 days post fertilization, dpf), 25\% epiboly (4 dpf), 30 somites (11 dpf), hatching (15 dpf), first feeding ( 46 days post hatching, dph), early metamorphosis ( 61 dph), climax metamorphosis ( 92 dph), and juvenile ( 112 dph). Halibut developmental staging was based on Pittman et al. [69] and Sæle et al. [1]. Total RNA was extracted from fresh or snap-frozen in liquid nitrogen samples using TRIzol Reagent (Invitrogen, Oslo, Norway). Total RNA integrity and quantity were checked using Bioanalyzer (Agilent Technologies, Waldbronn, Germany).

\section{Small RNAs library preparation and sequencing}

Libraries of small RNAs were prepared by the SOLiD ${ }^{\mathrm{TM}}$ small RNA expression kit, SREK (Applied Biosystems, Austin, Texas, USA) in accordance with the manufacturer's recommendations. In brief, Total RNAs were mixed with adapter mix A for $16 \mathrm{~h}$ ligation, which allowed sequencing from the 5' end of small RNAs, followed by reverse transcription and RNase $\mathrm{H}$ treatment. Libraries of cDNA were prepared using barcoded 3' primers for downstream sample multiplexing. Based on a trial PCR, large scale PCRs were performed with the following PCR cycle adjustments: 18 cycles for blastula stage, 17 cycles for epiboly stage, 16 cycles for hatching stage and 15 cycles for the remaining samples. These adaptor-ligated PCR products were then size-selected (105 - $150 \mathrm{bp)}$ using 6\% PAGE gel (Invitrogen), quantified using a Bioanalyzer (Agilent Technologies) and standardized to obtain DNA libraries that were suitable for emulsion PCR. Samples were run on half a slide in two quadrants with 50 nucleotides read length on the SOLiD 3 system (Applied Biosystems).

\section{Cloning of miRNAs}

Small RNA constituents of pooled RNAs from the eight developmental stages were recovered using flashPAGE fractionators (Ambion, Austin, Texas, USA) following the manufacturer's protocol. The recovered small RNA was ligated to adapter mix A of small RNA expression kit and reverse transcribed. cDNA was PCR amplified under the following thermal cycle conditions: initial denaturation of $95^{\circ} \mathrm{C}$ for $5 \mathrm{~min}$, followed by 18 cycles of $95^{\circ} \mathrm{C}$ for $30 \mathrm{~s}, 62^{\circ} \mathrm{C}$ for $30 \mathrm{~s}$, and $72^{\circ} \mathrm{C}$ for $30 \mathrm{~s}$, and final extension of $72^{\circ} \mathrm{C}$ for $7 \mathrm{~min}$. The product was run on $6 \%$ native PAGE and the product within the size range 105 - 150 bp was excised and eluted from the gel. The eluted product was cloned into psTBlue-1 AccepTor Vector (Novagen, Darmstadt, Germany) and transformed to NovaBlue Singles Competent Cells (Novagen). Positive colonies were collected and PCR was performed with T7 (5'-CTAATACGACTCACTATAGGG) and sp6 (5'-TCTATAGTGTCACCTAAAT) primers using 35 cycles of $94^{\circ} \mathrm{C}$ for $1 \mathrm{~min}, 55^{\circ} \mathrm{C}$ for $1 \mathrm{~min}$, and $72^{\circ} \mathrm{C}$ for 2 min, and final extension of $72^{\circ} \mathrm{C}$ for $5 \mathrm{~min}$. Positive clones were sequenced using $\mathrm{T} 7$ primer.

\section{Identification of conserved and novel miRNAs}

The trimmed reads were analyzed using the RNA2map (version 0.5.0) pipeline (Applied Biosystems Community Software). In short, reads corresponding to tRNA, rRNA, mtRNA, and adaptor sequences were filtered out using 25 seed length and 2 color mismatches. The remaining reads were mapped against Pisces (zebrafish, fugu, and tetraodon) and human miRBase release 16 [6] 
using 20 seed length and 2 color mismatches. The remaining reads were mapped against Atlantic halibut ESTs. All forward mapped reads with size in between 17 and $26 \mathrm{nts}$ were considered as legitimate miRNAs, if they had five and above counts at least in one of the investigated developmental stages. Known miRNAs were further analyzed for length and nucleotide composition. Each miRNA was aligned separately and checked for nucleotide composition and missed bases. All truncated miRNAs with more than 5 missed bases from 3'end and more than 1 missed base from 5 ' end were removed from the dataset.

Since Atlantic halibut genome has not been sequenced yet, our approach to identify novel miRNAs was through homologous search against miRNA databases by allowing two nucleotides mismatches inside the seed sequences and considering the reverse complementary sequences as well as checking for miRNA* sequences that were not characterized. Reads were considered as legitimate novel mature miRNAs when mismatches were found within seed sequences and had above 1000 read counts in total.

The other approach to find novel miRNAs was computational prediction from Atlantic halibut ESTs and GSS downloaded from NCBI (http://www.ncbi.nlm.nih. gov/sites/entrez). We used stringent criteria to avoid false positive by putting multilayer screening. Briefly, vector sequences from EST data were removed and clustered by TGICL [70]. The expected precursor sequences were extracted from the EST and GSS sequences using srnaloop [71] under similar criteria as in Li et al. [72] with some modifications. The modifications were done based on fish precursor miRNA in miRBase, which showed average GC \% in between 30\% and $70 \%$, average length 86 with range between $62-132$ nts, and $\mathrm{mfe}<-25 \mathrm{kcal} / \mathrm{mol}$. Further filtration steps were deployed using MiPred, which uses mfe and machine learning methods to discriminate real miRNAs from random miRNAs [73]. Only real precursor miRNAs were fetched from MiPred results. Each sequence was checked manually and sequence containing ambiguous bases, stretches of nucleotides and repeats were removed. Then candidate precursor miRNAs from EST were blasted against candidate precursor miRNA from GSS to filter out redundancies. Non redundant candidate miRNA precursors were blasted against miRBase stem-loop sequences database (downloaded from miRBase release 16). A blast result was classified as a legitimate known candidate precursor miRNA when a query sequence were mapped with single mismatch in 14 nucleotides and more than $80 \%$ of its length was covered by the alignment with e-value $<0.1$. Sequences without significant matches were used as putative precursor miRNAs. miRBase unmapped reads were mapped to these sequences using RNA2map with the same parameters as above. If sequences were mapped at the same positions outside the big loop region with more than 50 reads, then the putative precursor sequences were considered as legitimate miRNA precursors.

\section{Read count normalization and isomiRs expression}

Numbers of reads were normalized using relative frequency of reads, that is, specific number of miRNA reads in a sample was divided by a total number of miRNA reads in the sample [74]. To be able to differentiate the expression of each miRNA and categorize them according to their expression pattern, a heatmap chart was drawn by transforming the normalized data to $\log 2$ scales for visualization purpose. Hierarchical clustering with Euclidean distance and average linkage algorithm was performed using $\mathrm{R}$-program version 2.12.0 [75].

Nine miRNAs with the highest read count were selected and analyzed for digital expression pattern of their isomiRs. IsomiRs were considered for this analysis only when they had above 1,000 reads with the relative frequency higher than 0.05 at least in one of the developmental stages. The relative frequency of each isomiR was calculated by dividing the number of reads of an isomiR in a sample by total number of reads of the miRNA.

\section{Reverse transcription quantitative polymerase chain reaction ( $R T-q P C R$ )}

RT-qPCR was used to validate the digital expression profile of selected miRNAs (let-7a, miR-9, miR-19b, miR-24, miR-122, miR-124, miR-145 and miR-430c) using the TaqMan ${ }^{\circledR}$ MicroRNA assay (Applied Biosystems, Foster City, Ca, USA) following the manufacturer's protocol. We used two technical and four biological replicates. Total RNA of each biological replicate was extracted from 8 embryos, 5 larvae and a juvenile. The reaction was performed on Light Cycler $480^{\circledR}$ (Roche Applied Science, Rotkreuz, Switzerland) using white 96 well plates with thermal cycle conditions of $95^{\circ} \mathrm{C}$ for 10 min, followed by 45 cycles of $95^{\circ} \mathrm{C}$ for $15 \mathrm{~s}$ and $60^{\circ} \mathrm{C}$ for $1 \mathrm{~min}$.

The expression values were calculated based on $\mathrm{Cq}$ values obtained from the light cycler with detection cutoff of 40 PCR cycles. Relative quantification was performed following Pfaffl's mathematical model [76]. The relative concentration of each sample was normalized according to Mestdagh et al. [77] using 5S RNA and U6 snoRNA as references. To meet the assumptions of parametric statistics, the data were cubic root transformed and statistical differences were computed with one-way ANOVA, followed by Tukey's HSD multiple comparison post-hoc test. $P$ values of $<0.05$ were 
considered as significant. Correlation between digital expression profiles and RT-qPCR data was estimated using Pearson product-moment correlation coefficient. All statistical analyses were performed using R software version 2.12.0 [75].

\section{Additional material}

\section{Additional file 1: Read counts for 8 developmental stages of} Atlantic halibut. The total number of raw sequence reads obtained from SOLiD sequencing and the number of usable reads for each developmental stage is given.

Additional file 2: Size distribution of mapped reads in Atlantic halibut deep sequencing data. Reads mapped to different databases: A) mitochondrial transcripts, rRNA, tRNA, other non-coding RNA; B) miRBase 16 and C) Atlantic halibut ESTs. The size distribution of mapped reads for each database is given.

Additional file 3: Identified conserved miRNAs. All identified conserved Atlantic halibut miRNAs along with miRBase name, nucleotide sequences and read counts for each investigated developmental stages are given. Lower case letters indicate mismatches comparing to references.

Additional file 4: miRNA diversity during early development of Atlantic halibut. The number of different types of miRNAs identified during 8 stages of Atlantic halibut development; increasing as the development progressed.

Additional file 5: IsomiR occurrence during early development of Atlantic halibut. All miRNAs having $\geq 0.01 \%$ truncation $/ \mathrm{s}$ or addition $/ \mathrm{s}$ in $5^{\prime}$ and/or $3^{\prime}$ ends are listed. The percentage of both template and non-template nucleotide changes (A, U, C, and G) are shown as percentage of total reads of a given miRNA.

Additional file 6: Cloned miRNA sequences and their frequency. Indentified conserved miRNAs using cloning technique and their frequencies. Nucleotide mismatches (green), additions (blue) or modifications (red) are found in some miRNAs.

\section{Acknowledgements}

We thank the University of Uppsala, Genome Center for providing the SOLiD next generation sequencing service. We also thank Dr. Liqun He of Life Technology, Sweden, for his contribution in solving problems related to RNA2map small RNA analysis tool. We are indebted to Bjørnar Eggen, Heidi Ludviksen, Sylvie Bolla and Tormod Skålsvik for their technical support. This work was supported by the Research Council of Norway [grants 182653/N10 and 165272/S40]. TTB thanks Research Council of Norway and University of Nordland for funding his PhD scholarship.

\section{Author details}

'University of Nordland, Faculty of Biosciences and Aquaculture, Postbox 1490, 8049 Bodø, Norway. ${ }^{2}$ University of Bergen, Department of Biomedicine, Postbox 7804, N-5020 Bergen, Norway. ${ }^{3}$ University of Troms $\varnothing$, Department of Medical Biology, Faculty of Health Sciences, 9037 Troms $\varnothing$, Norway.

\section{Authors' contributions}

TTB performed sampling, laboratory work, data analysis, and drafted and revised the manuscript. CFCL participated in sampling and commented on the draft manuscript. BOK and TF were involved in bioinformatics. JMOF and SDJ participated in planning the study and manuscript organization. IB coordinated the study in all stages and revised the manuscript. All authors approved the final manuscript.

Received: 27 July 2011 Accepted: 10 January 2012 Published: 10 January 2012
References

1. Sæle $\varnothing$, Solbakken JS, Watanabe K, Hamre K, Power D, Pittman K: Staging of Atlantic halibut (Hippoglossus hippoglossus L.) from first feeding through metamorphosis, including cranial ossification independent of eye migration. Aquaculture 2004, 239(1-4):445-465.

2. Pittman K, Skiftesvik A, Berg L: Morphological and behavioural development of halibut, Hippoglossus hippoglossus (L.) larvae. J Fish Biol 1990, 37(3):455-472.

3. Wightman B, Ha I, Ruvkun G: Posttranscriptional regulation of the heterochronic gene Lin-14 by Lin-4 mediates temporal patternformation in C. elegans. Cell 1993, 75(5):855-862.

4. Lee RC, Feinbaum RL, Ambros V: The C. elegans heterochronic gene lin-4 encodes small RNAs with antisense complementarity to lin-14. Cell 1993, 75(5):843-854

5. Wienholds E, Plasterk RHA: MicroRNA function in animal development. FEBS Lett 2005, 579(26):5911-5922.

6. Griffiths-Jones S, Saini HK, van Dongen S, Enright AJ: miRBase: tools for microRNA genomics. Nucleic Acids Res 2008, 36:D154-D158

7. Cerda J, Douglas S, Reith M: Genomic resources for flatfish research and their applications. J Fish Biol 2010, 77(5):1045-1070.

8. Johansen SD, Karlsen BO, Furmanek T, Andreassen M, Jorgensen TE, Bizuayehu TT, Breines R, Emblem A, Kettunen P, Luukko K, et al: RNA deep sequencing of the Atlantic cod transcriptome. Comp Biochem Physiol DGenomics Proteomics 2011, 6(1):18-22.

9. Fu YS, Shi ZY, Wu ML, Zhang JL, Jia L, Chen XW: Identification and Differential Expression of MicroRNAs during Metamorphosis of the Japanese Flounder (Paralichthys olivaceus). PLOS ONE 2011, 6(7).

10. Xia JH, He XP, Bai ZY, Yue GH: Identification and Characterization of 63 MicroRNAs in the Asian Seabass Lates calcarifer. PLOS ONE 2011, 6(3):11.

11. Giraldez AJ, Mishima Y, Rihel J, Grocock RJ, Van Dongen S, Inoue K, Enright AJ, Schier AF: Zebrafish MiR-430 promotes deadenylation and clearance of maternal mRNAs. Science 2006, 312(5770):75-79.

12. Mishima Y, Giraldez AJ, Takeda Y, Fujiwara T, Sakamoto H, Schier AF, Inoue K: Differential regulation of germline mRNAs in soma and germ cells by zebrafish miR-430. Curr Biol 2006, 16(21):2135-2142.

13. Schier AF, Giraldez AJ: MicroRNA Function and Mechanism: Insights from Zebra Fish. Cold Spring Harbor symposia on Quantitative Biology 2006, LXXI:9.

14. Tani S, Kusakabe R, Naruse K, Sakamoto H, Inoue K: Genomic organization and embryonic expression of miR-430 in medaka (Oryzias latipes): Insights into the post-transcriptional gene regulation in early development. Gene 2010, 449(1-2):41-49.

15. Ason B, Darnell DK, Wittbrodt B, Berezikov E, Kloosterman WP, Wittbrodt Antin PB, Plasterk RHA: Differences in vertebrate microRNA expression. $P$ Natl A Sci USA 2006, 103(39):14385-14389.

16. Lee LW, Zhang S, Etheridge A, Ma L, Martin D, Galas D, Wang K: Complexity of the microRNA repertoire revealed by next-generation sequencing. RNA 2010, 16(11):2170-2180.

17. Kuchenbauer F, Morin RD, Argiropoulos B, Petriv Ol, Griffith M, Heuser M, Yung E, Piper J, Delaney A, Prabhu AL, et al: In-depth characterization of the microRNA transcriptome in a leukemia progression model. Genome Res 2008, 18(11):1787-1797.

18. Fernandez-Valverde SL, Taft RJ, Mattick JS: Dynamic isomiR regulation in Drosophila development. RNA-Publ RNA Soc 2010, 16(10):1881-1888.

19. Luciano DJ, Mirsky H, Vendetti NJ, Maas S: RNA editing of a miRNA precursor. RNA-Publ RNA Soc 2004, 10(8):1174-1177.

20. Kawahara Y, Zinshteyn B, Sethupathy P, lizasa H, Hatzigeorgiou AG, Nishikura K: Redirection of silencing targets by adenosine-to-inosine editing of miRNAs. Science 2007, 315(5815):1137-1140.

21. Kawahara Y, Megraw M, Kreider E, lizasa H, Valente L, Hatzigeorgiou AG, Nishikura K: Frequency and fate of microRNA editing in human brain. Nucleic Acids Res 2008, 36(16):5270-5280.

22. Ramachandran $\mathrm{V}$, Chen XM: Degradation of microRNAs by a family of exoribonucleases in Arabidopsis. Science 2008, 321(5895):1490-1492.

23. Katoh T, Sakaguchi Y, Miyauchi K, Suzuki T, Kashiwabara S, Baba T: Selective stabilization of mammalian microRNAs by 3 ' adenylation mediated by the cytoplasmic poly(A) polymerase GLD-2. Genes Dev 2009, 23(4):433-438

24. Starega-Roslan J, Krol J, Koscianska E, Kozlowski P, Szlachcic WJ, Sobczak K, Krzyzosiak WJ: Structural basis of microRNA length variety. Nucleic Acids Res 2011, 39(1):257-268. 
25. Kai ZS, Pasquinelli AE: MicroRNA assassins: factors that regulate the disappearance of miRNAs. Nat Struct Mol Biol 2010, 17(1):5-10.

26. Landgraf $P$, Rusu M, Sheridan R, Sewer A, lovino N, Aravin A, Pfeffer S, Rice A, Kamphorst AO, Landthaler M, et al: A mammalian microRNA expression atlas based on small RNA library sequencing. Cell 2007, 129(7):1401-1414.

27. Marti E, Pantano L, Banez-Coronel M, Llorens F, Minones-Moyano E, Porta S, Sumoy L, Ferrer I, Estivill X: A myriad of miRNA variants in control and Huntington's disease brain regions detected by massively parallel sequencing. Nucleic Acids Res 2010, 38(20):7219-7235.

28. Cai YM, Yu XM, Zhou Q, Yu CX, Hu HY, Liu JC, Lin HB, Yang J, Zhang B, Cui $P$, et al: Novel microRNAs in silkworm (Bombyx mori). Funct Integr Genomic 2010, 10(3):405-415.

29. Qi YH, Tu J, Cui LB, Guo XL, Shi ZY, Li SC, Shi WT, Shan YF, Ge YY, Shan J, et al: High-Throughput Sequencing of MicroRNAs in Adenovirus Type 3 Infected Human Laryngeal Epithelial Cells. J Biomed Biotechnol 2010.

30. Jagadeeswaran G, Zheng Y, Sumathipala N, Jiang HB, Arrese EL, Soulages JL, Zhang WX, Sunkar R: Deep sequencing of small RNA libraries reveals dynamic regulation of conserved and novel microRNAs and microRNA-stars during silkworm development. BMC Genomics 2010, 11:18

31. Schulte JH, Marschall T, Martin M, Rosenstiel P, Mestdagh P, Schlierf S, Thor T, Vandesompele J, Eggert A, Schreiber $S$, et al: Deep sequencing reveals differential expression of microRNAs in favorable versus unfavorable neuroblastoma. Nucleic Acids Res 2010.

32. Galloway T, Bardal T, Kvam S, Dahle S, Nesse G, Randol M, Kjorsvik E, Andersen $\mathrm{O}$ : Somite formation and expression of MyoD, myogenin and myosin in Atlantic halibut (Hippoglossus hippoglossus L.) embryos incubated at different temperatures: transient asymmetric expression of MyoD. J Exp Biol 2006, 209(13):2432-2441.

33. Bai JL, Solberg C, Fernandes JMO, Johnston IA: Profiling of maternal and developmental-stage specific mRNA transcripts in Atlantic halibut Hippoglossus hippoglossus. Gene 2007, 386(1-2):202-210.

34. Hildahl J, Galay-Burgos M, Sweeney G, Einarsdottir IE, Bjornsson BT: Identification of two isoforms of Atlantic halibut insulin-like growth factor-I receptor genes and quantitative gene expression during metamorphosis. Comp Biochem Physiol B-Biochem Mol Biol 2007. 147(3):395-401.

35. Douglas SE, Knickle LC, Williams J, Flight RM, Reith ME: A first generation Atlantic halibut Hippoglossus hippoglossus (L.) microarray: application to developmental studies. J Fish Biol 2008, 72(9):2391-2406.

36. Lagos-Quintana M, Rauhut R, Yalcin A, Meyer J, Lendeckel W, Tuschl T: Identification of tissue-specific microRNAs from mouse. Curr Biol 2002, 12(9):735-739.

37. Darnell DK, Kaur S, Stanislaw S, Konieczka JK, Yatskievych TA, Antin PB: MicroRNA expression during chick embryo development. Dev Dyn 2006, 235(11):3156-3165.

38. Giraldez AJ, Cinalli RM, Glasner ME, Enright AJ, Thomson JM, Baskerville S, Hammond SM, Bartel DP, Schier AF: MicroRNAs regulate brain morphogenesis in zebrafish. Science 2005, 308(5723):833-838.

39. Soares A, Pereira P, Santos B, Egas C, Gomes A, Arrais J, Oliveira J, Moura G, Santos M: Parallel DNA pyrosequencing unveils new zebrafish microRNAs. Bmc Genomics 2009, 10(1):195.

40. Lagos-Quintana M, Rauhut R, Lendeckel W, Tuschl T: Identification of novel genes coding for small expressed RNAs. Science 2001, 294(5543):853-858.

41. Carrington JC, Ambros V: Role of microRNAs in plant and animal development. Science 2003, 301(5631):336-338.

42. Krichevsky AM, King KS, Donahue CP, Khrapko K, Kosik KS: A microRNA array reveals extensive regulation of microRNAs during brain development. RNA-Publ RNA Soc 2003, 9(10):1274-1281.

43. Chen PY, Manninga H, Slanchev K, Chien M, Russo JJ, Ju J, Sheridan R, John B, Marks DS, Gaidatzis D, et al: The developmental miRNA profiles of zebrafish as determined by small RNA cloning. Genes Dev 2005, 19(11):1288-1293.

44. Chen JF, Mandel EM, Thomson JM, Wu QL, Callis TE, Hammond SM, Conlon FL, Wang DZ: The role of microRNA-1 and microRNA-133 in skeletal muscle proliferation and differentiation. Nature Genet 2006, 38(2):228-233.

45. Telford NA, Watson AJ, Schultz GA: Transition from maternal to embryonic control in early mammalian development - a comparison of several species. Mol Reprod Dev 1990, 26(1):90-100.
46. Tadros W, Lipshitz HD: The maternal-to-zygotic transition: a play in two acts. Development 2009, 136(18):3033-3042.

47. Kloosterman WP, Steiner FA, Berezikov E, de Bruijn E, van de Belt J, Verheul M, Cuppen E, Plasterk RHA: Cloning and expression of new microRNAs from zebrafish. Nucleic Acids Res 2006, 34(9):2558-2569.

48. Mommens M, Fernandes J, Bizuayehu T, Bolla S, Johnston I, Babiak I: Maternal gene expression in Atlantic halibut (Hippoglossus hippoglossus L.) and its relation to egg quality. BMC Res Notes 2010, 3(1):138.

49. Ventura A, Young AG, Winslow MM, Lintault L, Meissner A, Erkeland SJ, Newman J, Bronson RT, Crowley D, Stone JR, et al: Targeted Deletion Reveals Essential and Overlapping Functions of the miR-17 92 Family of miRNA Clusters. Cell 2008, 132(5):875-886.

50. Foshay KM, Gallicano Gl: miR-17 family miRNAs are expressed during early mammalian development and regulate stem cell differentiation. Dev Biol 2009, 326(2):431-443.

51. Lagos-quintana M, Rauhut R, Meyer J, Borkhardt A, Tuschl T: New microRNAs from mouse and human. RNA 2003, 9(2):175-179.

52. He XJ, Yan YL, Eberhart JK, Herpin A, Wagner TU, Schartl M, Postlethwait JH: miR-196 regulates axial patterning and pectoral appendage initiation. Dev Biol 2011, 357(2):463-477.

53. Chen Y, Gorski DH: Regulation of angiogenesis through a microRNA (miR-130a) that down-regulates antiangiogenic homeobox genes GAX and HOXA5. Blood 2008, 111(3):1217-1226.

54. Kapsimali M, Kloosterman WP, de Bruijn E, Rosa F, Plasterk RHA, Wilson SW: MicroRNAs show a wide diversity of expression profiles in the developing and mature central nervous system. Genome Biol 2007, 8(8):16.

55. Liao YL, Lonnerdal B: Global MicroRNA Characterization Reveals That miR103 Is Involved in IGF-1 Stimulated Mouse Intestinal Cell Proliferation. PLOS ONE 2010, 5(9).

56. Bianchi N, Zuccato C, Lampronti I, Borgatti M, Gambari R: Expression of miR-210 during erythroid differentiation and induction of gamma-globin gene expression. BMB Rep 2009, 42(8):493-499.

57. Pase L, Layton JE, Kloosterman WP, Carradice D, Waterhouse PM, Lieschke GJ: miR-451 regulates zebrafish erythroid maturation in vivo via its target gata2. Blood 2009, 113(8):1794-1804

58. Yang G-H, Wang F, YU J, Wang X-S, Yuan J-Y, Zhang J-W: MicroRNAs are involved in erythroid differentiation control. J Cell Biochem 2009, 107(3):548-556.

59. Guo L, Lu Z: The Fate of miRNA* Strand through Evolutionary Analysis: Implication for Degradation As Merely Carrier Strand or Potential Regulatory Molecule? PLOS ONE 2010, 5(6):e11387.

60. Berezikov E, Robine N, Samsonova A, Westholm JO, Naqvi A, Hung J-H, Okamura K, Dai Q, Bortolamiol-Becet D, Martin R, et al: Deep annotation of Drosophila melanogaster microRNAs yields insights into their processing, modification, and emergence. Genome Res 2011, 21(2):203-215

61. Morin RD, O'Connor MD, Griffith M, Kuchenbauer F, Delaney A, Prabhu A-L, Zhao Y, McDonald H, Zeng T, Hirst M, et al: Application of massively parallel sequencing to microRNA profiling and discovery in human embryonic stem cells. Genome Res 2008, 18(4):610-621.

62. Ebhardt HA, Tsang HH, Dai DC, Liu YF, Bostan B, Fahlman RP: Meta-analysis of small RNA-sequencing errors reveals ubiquitous post-transcriptional RNA modifications. Nucleic Acids Res 2009, 37(8):2461-2470.

63. Jones MR, Quinton $L$, Blahna MT, Neilson JR, Fu S, Ivanov AR, Wolf DA, Mizgerd JP: Zcchc11-dependent uridylation of microRNA directs cytokine expression. Nat Cell Biol 2009, 11(9):1157-1163.

64. Burroughs AM, Ando Y, de Hoon MJL, Tomaru Y, Nishibu T, Ukekawa R, Funakoshi T, Kurokawa T, Suzuki H, Hayashizaki Y, et al: A comprehensive survey of $3^{\prime}$ animal miRNA modification events and a possible role for $3^{\prime}$ adenylation in modulating miRNA targeting effectiveness. Genome Res 2010, 20(10):1398-1410.

65. Yue JM, Sheng Y, Orwig KE: Identification of novel homologous microRNA genes in the rhesus macaque genome. BMC Genomics 2008, 9.

66. Berezikov E, Guryev V, van de Belt J, Wienholds E, Plasterk RHA, Cuppen E: Phylogenetic shadowing and computational identification of human microRNA genes. Cell 2005, 120(1):21-24.

67. Stark A, Bushati N, Jan CH, Kheradpour P, Hodges E, Brennecke J, Bartel DP, Cohen SM, Kellis M: A single Hox locus in Drosophila produces functional microRNAs from opposite DNA strands. Genes Dev 2008, 22(1):8-13. 
68. Babiak I, Ottesen O, Rudolfsen G, Johnsen S: Quantitative characteristics of Atlantic halibut, Hippoglossus hippoglossus L., semen throughout the reproductive season. Theriogenology 2006, 65(8):1587-1604.

69. Pittman K, Bergh $\varnothing$, Opstad I, Skiftesvik AB, Skjolddal L, Strand H: Development of eggs and yolk sac larvae of halibut (Hippoglossus hippoglossus L.). J Appl Icht 1990, 6(3):142-160.

70. Pertea G, Huang X, Liang F, Antonescu V, Sultana R, Karamycheva S, Lee Y, White J, Cheung F, Parvizi B, et al: TIGR Gene Indices clustering tools (TGICL): a software system for fast clustering of large EST datasets. Bioinformatics 2003, 19(5):651-652.

71. Grad Y, Aach J, Hayes GD, Reinhart BJ, Church GM, Ruvkun G, Kim J: Computational and Experimental Identification of $\mathrm{C}$. elegans microRNAs. Mol Cell 2003, 11(5):1253-1263.

72. Li S-C, Pan C-Y, Lin W-c: Bioinformatic discovery of microRNA precursors from human ESTs and introns. BMC Genomics 2006, 7(1):164.

73. Jiang $P$, Wu $H$, Wang W, Ma W, Sun X, Lu Z: MiPred: classification of real and pseudo microRNA precursors using random forest prediction model with combined features. Nucleic Acids Res 2007, 35:W339-W344.

74. Linsen SEV, de Wit E, Janssens G, Heater S, Chapman L, Parkin RK, Fritz B, Wyman SK, de Bruijn E, Voest EE, et al: Limitations and possibilities of small RNa digital gene expression profiling. Nat Methods 2009, 6(7):474-476.

75. The R Project for Statistical Computing. [http://www.r-project.org/]

76. Pfaffl MW: A new mathematical model for relative quantification in realtime RT-PCR. Nucleic Acids Res 2001, 29(9):6.

77. Mestdagh P, Van Vlierberghe P, De Weer A, Muth D, Westermann F, Speleman F, Vandesompele J: A novel and universal method for microRNA RT-qPCR data normalization. Genome Biol 2009, 10(6):R64.

doi:10.1186/1471-2164-13-11

Cite this article as: Bizuayehu et al:: Differential expression patterns of conserved miRNAs and isomiRs during Atlantic halibut development. BMC Genomics 2012 13:11.

\section{Submit your next manuscript to BioMed Central and take full advantage of:}

- Convenient online submission

- Thorough peer review

- No space constraints or color figure charges

- Immediate publication on acceptance

- Inclusion in PubMed, CAS, Scopus and Google Scholar

- Research which is freely available for redistribution

Submit your manuscript at www.biomedcentral.com/submit
C Biomed Central 